\title{
O tempo das expectativas decrescentes, ou os efeitos políticos do presentismo
}

The time of decreasing expectations, or the political effects of presentism

ARANTES. Paulo E. O novo tempo do mundo: e outros estudos sobre a era da emergência. São Paulo: Boitempo, 2014. 464p.

\section{Guiherme Bianchi}

guilhermebianchix@gmail.com

Doutorando em História

Universidade Federal de Ouro Preto

Rua Bicame, 40A - Passagem de Mariana

35420-000 - Mariana - Minas Gerais

Brasil

Palavras-chave

Tempo; Política; Presentismo.

Keywords

Time; Politics; Presentism. 
Não se trata de uma grande novidade a anunciação da modernidade pósGuerra Fria como um tempo no qual a urgência se estabelece como fundamento central de projetos políticos ou de compreensões temporais. É possível encontrar tal diagnóstico nas obras de autores com pressupostos teóricos dos mais diferentes, como Giorgio Agamben, Naomi Klein, Roberto Esposito ou Robert Kurz, apenas para citar alguns. A pergunta que vem imediatamente para o leitor familiarizado com tais perspectivas (ou mesmo com diagnósticos mais antigos que já apresentavam tal horizonte compreensivo, como em Walter Benjamin ou Carl Schmitt) parece ser: afinal, em que sentido a proposição de Paulo Arantes em $O$ novo tempo do mundo, acerca do contemporâneo como uma "era de expectativas decrescentes", apresenta algo de novo em relação aos diagnósticos mais sedimentados pela crítica?

O livro em questão se trata da junção de dois materiais inéditos do autor (o capítulo inicial e o capítulo final) com artigos publicados ao longo dos últimos 10 anos. Daí a variedade de temas que circundam a reflexão de Paulo Arantes, variedade essa que não deixa se confundir como mero rol de exemplificações de uma tese central. Cada tema e subtema do livro, como veremos, possuem tanto a capacidade de prover força ao argumento apresentado, como também de representar em si possibilidades críticas que intensifiquem ou sobreponham o próprio núcleo de tal argumento. O que vemos ao longo do livro é uma espécie de exercício dialético negativo fiel à lição de Adorno, para quem a filosofia consistia "no esforço do conceito em curar as feridas que, necessariamente, inflige o próprio conceito" (ADORNO 1983, p. 43).

Professor aposentado do Departamento de Filosofia da Universidade de São Paulo, Paulo Arantes é reconhecido pela fertilidade de escritos capazes de conjugar história da filosofia, como em seus livros Hegel: a Ordem do Tempo (1981) e Ressentimento da Dialética (1996), com questões candentes da vida nacional, inflexão melhor observada em seus livros Um departamento francês de ultramar (1994) e O Fio da Meada (1996). Seu amigo (e feroz crítico) Ruy Fausto (2014, p. 92) chega a definir essa inflexão como ponto de mutação nas compressões filosóficas de Arantes mais à esquerda: "Excelente professor, homem de esquerda como muito de seus pares, a partir daquela quadra enveredou por um caminho original". O caminho original do qual fala Ruy Fausto seria o trajeto entre uma filosofia crítica para uma atitude "antifilosófica" ou "niilista", "indo parar lá onde estava o Marx da Ideologia Alemã".

Publicado em abril de 2014 pela Editora Boitempo na coleção organizada pelo próprio Arantes ("Coleção Estado de Sítio"), o livro surge como realização conceitual de uma percepção aguda em relação ao passado recente e ao presente global. Para o autor, nossa experiência contemporânea está cada vez mais baseada no decréscimo das expectativas de futuros qualitativamente diferentes. O paradigma securitário de um mundo completamente entregue à lógica da urgência só teria significado até agora políticas reprodutivas de um projeto de mundo tal como dado pela lógica da acumulação. Essa dinâmica temporal do capitalismo (já que a economia política detém ainda centralidade explicativa para Arantes) é orientada para o futuro, mas um futuro que nada apresenta 
de novo, que apenas reforça a necessidade do presente: "[...] essa forma de dominação através da dinâmica temporal que vem a ser o capitalismo tende paradoxalmente a se tornar cada vez mais presentista" (ARANTES 2014, p. 72).

O presentismo do qual fala Paulo Arantes detém particularidades em relação ao entendimento dado pelo historiador francês François Hartog, e tal diferenciação talvez seja fundamental para compreender o que há de original no seu argumento. Se tanto em Hartog como em Arantes a ideia de presentismo aparece como a absolutização do presente como categoria dominante de orientação histórica (e Arantes toma ciência dessa similitude, cf. ARANTES 2014, p. 167-171), a distância entre as percepções dos dois autores parece ser mais significativa que suas potenciais semelhanças. O fato é que, se Arantes articula em seu livro a percepção de um horizonte temporal do sistemamundo, as diferenciações territoriais e espaciais são centrais na construção de seu argumento. A preocupação da realidade brasileira interessa de modo fundamental ao autor. A progressiva demanda de desenvolvimentismo e de fortalecimento de dinâmicas direcionais ao futuro (projetos que só podem ser garantidos inteiramente pela reafirmação da ordem e da exceção) ${ }^{1}$ não podem senão demonstrar que o paradigma direcional sobrevive, ainda que só possa ser garantido pela repetição incessante das condições materiais do presente. Mais do que uma ferramenta heurística de compreensão histórica (tal como intencionada por Hartog), o presentismo de qual fala Arantes é, na verdade, uma evidência da experiência histórica do presente e, portanto, detém tanto um 142 potencial analítico como prático.

Com um extensivo capítulo inicial dedicado à demonstração da configuração conceitual do "novo tempo do mundo", Arantes dedica-se a apresentar para seus leitores a hipótese koselleckiana de redefinição do tempo moderno articulado entre as chaves "espaço de experiência" ou "horizonte de expectativa". Hipótese já conhecida entre historiadores, Arantes parece esmiuçá-la para um público que não a conhece tão profundamente. A retomada do arsenal analítico de Reinhart Koselleck tem o mérito de não reduzi-lo a simples sistema explicativo encerrado em si mesmo, pois é verdade que poderia ser questionado o perigo epistêmico inscrito na utilização gratuita das categorias do autor alemão como garantia política ou ética de certa coloração de valor do tempo histórico recente; creio, porém, não ser o caso, como fica claro quando o autor inclui, a partir de um comentário do historiador norteamericano Stephen Kern, uma diferenciação entre duas formas distintas de se relacionar com o futuro imediato. Além da chave koselleckiana "expectativa", o autor sugere a inclusão de uma outra, "atividade": enquanto a primeira se caracterizaria por um futuro que vem de encontro ao sujeito, "contrapondose a um ambiente a princípio hostil e todo-poderoso", a ideia de "atividade" pressuporia um sujeito que se lança ao futuro, de modo a obter algum possível controle sobre os acontecimentos (ARANTES 2014, p. 86). 
Mais que um complemento ao fundamento heurístico de Koselleck, o que tal inclusão significa é uma complexificação possível decorrente da formulação original do pensador alemão. É que Arantes nota, ao longo do primeiro capítulo, que a novidade apresentada pela chave analítica da "atividade" vem a ser a própria ideia do sujeito liberal em colonizar o futuro entreaberto pelas seguranças materiais garantidas pelo presente (segurança de propriedade, segurança bélica ou segurança contra "os inimigos"). A "expectativa" serviria mais para compreender a lógica de ação do sujeito de tipo hobbesiano, dotado de medo que acompanha a imaginação do futuro possível, onde esse futuro aparece como "fonte perene de insegurança". O indivíduo moderno seria sempre resultado de combinação dessas duas orientações em relação ao futuro.

Afirmando a centralidade da Guerra Fria como "último horizonte de expectativa dos tempos modernos" (ARANTES 2014, p. 91), o capítulo se encerra com a sugestão de que instaura-se, nesse passado recente, uma lógica mundial dominada pelo paradigma do instante. Tal paradigma caracterizar-seia por uma ação política incapaz (ou desinteressada) em se movimentar pelas distâncias que separariam a experiência da expectativa, de modo que substituise a política direcionada para possíveis transformações qualitativas pela mera "gestão dos destroços do presente" (ARANTES 2014, p. 91).

No segundo capítulo, Arantes prossegue na construção de seu arsenal crítico, primeiramente sob a forma do nível estrutural da sociabilidade pelo trabalho como fio condutor de um novo tempo do mundo, no qual a finalidade abstrata da produção aparece como a perfeita "banalização do mal" como regra social do contemporâneo. A semelhança com a tese de Giorgio Agamben acerca do campo de concentração como paradigma político do capitalismo tardio não é mero acaso. Tal como o filósofo italiano, Arantes articula comparações entre os dois momentos históricos. O colaboracionismo nazista é colocado ao lado de um suposto colaboracionismo nas estruturas organizacionais de nosso mundo, que gravita em torno do trabalho. Se no nazismo todo mal poderia ser justificado através do elemento discursivo do inimigo; o "grande Outro" no caso de nosso tempo parece brotar de seu próprio seio, sob a forma de um "trabalho repetitivo coagido pelos cronômetros".

O interlocutor de Arantes aqui é o psicólogo e psicanalista francês Christophe Dejours que, em seu livro Souffrance en France - La banalisation de l'injustice sociale, sugeriu as conexões psíquicas e sociais entre o tipo de trabalho organizacional praticado no Ocidente contemporâneo e a intensificação de doenças ligadas ao trabalho, como a depressão e a ansiedade. Observando uma lógica de trabalho incapaz de se reproduzir positivamente em nosso mundo, já que a transformação de valor em mais-valor vê-se cada dia mais incapaz de sustentar novos ciclos econômicos produtivos, Arantes pode articular nas entrelinhas de seu texto a crítica dessa "gestão do sofrimento social" com aquela lógica temporal de um mundo que não pode ser nada além de um reflexo de si mesmo. O fundamento do que ele chama de "tempo intemporal" não pode senão naturalizar uma ideia de humanidade cuja única função é garantir a reprodução da lógica do presente. 
A segunda parte do capítulo, intitulada "Zonas de Espera: uma digressão sobre o tempo morto da onda punitiva contemporânea", propõe a reflexão sobre outra forma de banalização do mal em nosso tempo: a transformação em regra social de lógicas punitivas típicas das sociedades de mercado. E aqui as exemplificações possíveis levantadas pelo autor são múltiplas, de modo que talvez valha a pena debruçarmo-nos principalmente sobre o ponto focal de sua argumentação, a saber, que a valorização do tempo (na verdade, valorização da espera) em nosso mundo aparece como sintoma primordial da mesma lógica de um tempo engessado. A consolidação de estruturas de controle jurídicopunitivas funciona como paradigma conceitual para Arantes, como se uma sociedade com um apreço pela punição como fim em si mesmo fosse também efeito de um tempo histórico morto, no qual todo futuro só é compreendido pela régua do presente. Mas esse tempo morto da espera punitiva é entendido pelo autor como uma questão de classe, já que afeta cada vez menos o topo da pirâmide social (não só a prisão como paradigma, mas o trato com os refugiados desterritorializados ou o sujeito preso nas estruturas burocráticas do poder).

O efeito disso é a valorização de uso das categorias de tempo. A paciência, o tempo em si, a lentidão se transformam em categorias de luxo, categorias mercantilizáveis, disponíveis apenas para aqueles que possam comprá-las. Mobilizando a partir disso o conceito de "atualismo", Paulo Arantes define que a caracterização de nosso presente desarticularia as dimensões koselleckianas de "espaço de experiência" e "horizonte de expectativa", já que em nosso mundo todo chamado à ação responderia por uma injunção imediata do instante, pois, "por mais frívolo que possa parecer o apelo presentista atual, seu protagonista é um personagem submerso por obrigações temporais exigíveis à queima-roupa" (ARANTES 2014, p. 159).

O segundo capítulo finaliza com uma reflexão paralela acerca da instauração da ordem e da exceção como medida protetiva nas democracias modernas, tomando as insurreições nos subúrbios franceses em 2005 como chave de leitura para sua hipótese de uma administração do medo da insegurança como paradigma normativo das democracias contemporâneas. Nessa altura do livro, Arantes parece estar preocupado em oferecer evidências históricas para a validação de sua hipótese, de modo que as revoltas no gueto francês e as medidas protetivas de segurança efetivadas para sua pacificação surgem como local de demonstração empírica acerca de como as relações entre tempo e ação são hoje rearticuladas a partir de uma temporalidade inscrita na ideia de segurança e, portanto, uma temporalidade que é filha do instante securitário. Os motins franceses funcionam para o autor também como exemplo do modo como o desespero, enquanto categoria psicológica das massas, representa um efeito a mais do que ele chama de um "curto-circuito da semântica da história" contemporânea (ARANTES 2014, p. 253).

O terceiro capítulo aparece segmentado em duas partes: "1964" (publicado originalmente no livro organizado por Vladimir Safatle e Edson Telles, $O$ que resta da ditadura: a exceção brasileira, de 2010) e "Tempos de exceção" (entrevista do autor publicada na revista Trans/Form/Ação em 2008). No 
primeiro, preocupado com as continuidades do regime de exceção brasileiro na sociedade pós-ditadura, Arantes refaz o caminho de uma transição incompleta, em que a antiga dominação pela coerção política se estabelece na sociedade democratizada como dominação via financeirização do social. A opressão desloca-se de medida preventiva de ordem e se intensifica como técnica de governo. Consciente de fáceis mal entendidos dessa hipótese, Arantes nota que a tese da continuidade não significa reiterar a existência de uma repetição incessante do período ditatorial. Se tais continuidades caracterizariam um regime jurídico-político em que a constitucionalidade é terreno sólido para as "classes confortáveis", o tratamento paternalista-punitivo de nosso tempo sobrevive para a "ralé". Na entrevista que se segue, Arantes avança na hipótese de um "estado de exceção permanente" na realidade brasileira. O termo, que à primeira vista pode ser lido como uma sintaxe contraditória, tem a potência de demonstrar a contradição existente nas próprias relações políticas e sociais. A hipótese aqui descortina as possíveis relações entre a figura constitucional do estado de exceção com a irrupção de novas lógicas de desenvolvimento econômico à brasileira. A transformação de uma economia industrial periférica em uma recente plataforma de valorização financeira exige a existência desse poder soberano sempre passível de ser ativado.

Ao fim, Arantes apresenta o que talvez seja o núcleo político mais imediato do seu argumento, com suas considerações acerca das "jornadas de junho" de 2013. Reconstituindo a gênese de Junho pelo prisma de uma insurgência cidadã gestada nos anos Lula, mostra-se preocupado em compreender os nós que ligam a fundamentação dessa cidadania ascendente, inscrita socialmente pela ascensão via consumo e casa própria típicas da última década, ao redor do urbano. O projeto carioca das Unidades de Polícia Pacificadora funcionam, na analítica de Arantes, como um aviso de incêndio do que estava por vir: o controle social, a pacificação, o adestramento de comunidades não estáveis aparece como efeito de uma gestão de territórios que pretendeu, em última estância, produzir indivíduos reduzidos à lógica nacional do consumo-produção (e permitir, no contexto específico dos megaeventos, uma circulação segura para alguns). O controle social da cidade aparece como momento essencial na conformação dessa nova ordem, é a sua negação ou sua positivação, em diferentes níveis, que aparecem como o fundamento de novas inscrições de participações políticas na análise de Arantes (as UPP, o financiamento estatal de moradias, a arte urbana, etc.), indivíduos que se tornam parte do mundo da cidadania. Entretanto, tais políticas falharam em levar em conta a igual necessidade de uma inclusão na mobilidade urbana ou na participação de constituição da cidade como lugar do plural - ou talvez essa fosse mesmo a sua função "natural", já que o argumento não fica tão claro; mas, "aí veio Junho" (ARANTES 2014, p. 387).

O fenômeno massivo de junho de 2013 aparece assim como um ponto de inflexão de uma história originária brasileira não reativa. É que, pela primeira vez, os cidadãos "entrincheirados" tornam-se cidadãos "insurgentes", sem a coreografia pré-determinada das Diretas Já ou dos caras-pintadas. As reivindicações em jogo, concentradas todas inicialmente na exigência de um 
direito à cidade, inscreve na semântica das lutas populares o próprio conceito da "insurgência", pois os sujeitos não são mais subversivos ou indignados. O efeito dessa transformação semântica, na hipótese do autor, desestabilizaria as próprias coordenadas temporais em jogo.

Após um desenvolvimento textual que poderia facilmente ser confundido com uma espécie de crítica negativa (para não dizer puro pessimismo) das opções políticas em jogo no contemporâneo, o final do livro apresenta possíveis horizontes de positividade na crítica do autor. A figura espectral de Junho aparece nesse momento como "ato profanatório", uma brecha possível na era das expectativas decrescentes. Se a doutrina contra insurgente da exceção e da pacificação cotidiana produz uma espécie de vácuo político, repetindo o gesto foucaultiano que dizia que onde há poder, há resistência, Arantes analisa as movimentações de massa de 2013, a despeito de seus problemas de origem inscritos numa politização que é filha da institucionalidade, como momento de liberação de uma carga de energia utópica, em que aquele horizonte remoto do não-contemporâneo produz a potência de transformar-se em utopia real. Junho passa a ser o horizonte de um mundo sem horizonte que, negando os dispositivos de controle da pacificação e dos pactos sociais das últimas décadas, apresentou novas formas e novos conteúdos do fazer-política.

Mas, como quase todo exercício dialético do autor, esse também tem um lado contrário. Ao invés de lançar uma positivação neutra às multidões de Junho, Arantes toma consciência dos perigos inscritos em sua própria natureza, pois,

146 por um lado, esse poder coletivo dos corpos na rua desafia o teórico preocupado com o caráter ético-político da mobilização coletiva. Restaria saber, ainda, se a insurgência da Multidão (a referência à Toni Negri e Michael Hardt é do autor) seria capaz de garantir, por si só, uma virada pragmática dessas ondas incendiárias em utopias políticas reais capazes de transformar o extraordinário em cotidiano, para remetermos aos termos do livro.

Munido de uma heterodoxia materialista crítica, o mérito da obra de Paulo Arantes parece ser-a conjugação da semântica dos tempos históricos de Koselleck e de seus predecessores com um engajamento crítico anticapitalista por excelência (confirmado pelas referências recorrentes a Anselm Jappe, Robert Kurz, Moishe Postone, etc.), recriando um fio que, no fundo, nunca deixou de estar ali - a relação entre tempo e dominação econômica. O livro denota, ainda, importantes sinais de que há processos de subjetivação em nosso mundo que tornam essa rede do tempo dominado pela lógica do presente dominante sempre passível de ser rasgada, recriada e ultrapassada.

\section{Referências bibliográficas}

ADORNO, Theodor. Terminologia filosófica. Tradução de Ricardo Sanchez Ortiz de Urbina. Madrid: Taurus Ediciones, 1983. t. 1.

ARANTES, P. E. Hegel: a ordem do tempo. São Paulo: Polis, 1981.

O novo tempo do mundo: e outros estudos sobre a era da emergência. São Paulo: Boitempo, 2014. 
. Ressentimento da dialética. São Paulo: Paz e Terra, 1996.

. Um departamento francês de ultramar. São Paulo: Paz e Terra, 1994.

O fio da meada. São Paulo: Paz e Terra, 1996.

FAUSTO, Ruy. A esquerda encapuçada. Revista Piauí, n. 99, p. 42-50, 2014. 